\title{
Does Government Intervention Affect CO2 Emission Reduction Effect of Producer Services Agglomeration? Empirical Analysis Based on Spatial
Dubin Model and Dynamic Threshold Model
}

\author{
Jinling Yan \\ Xinjiang University \\ Xiaodong Yang \\ Xinjiang University \\ Chunxia Nie \\ National Development and Reform Commission \\ Xufeng Su \\ Xinjiang University \\ Junfeng Zhao ( $\nabla$ zjf@ctbu.edu.cn ) \\ Xinjiang University
}

Qiying Ran

Shanghai Business School

\section{Research Article}

Keywords: PSA, Government intervention, China's CO2 emissions, Spatial Dubin model, Dynamic threshold model

Posted Date: January 17th, 2022

DOI: https://doi.org/10.21203/rs.3.rs-1140166/v1

License: (c) (i) This work is licensed under a Creative Commons Attribution 4.0 International License. Read Full License 


\section{Does government intervention affect $\mathrm{CO}_{2}$ emission reduction effect of} producer services agglomeration? Empirical analysis based on spatial Dubin model and dynamic threshold model

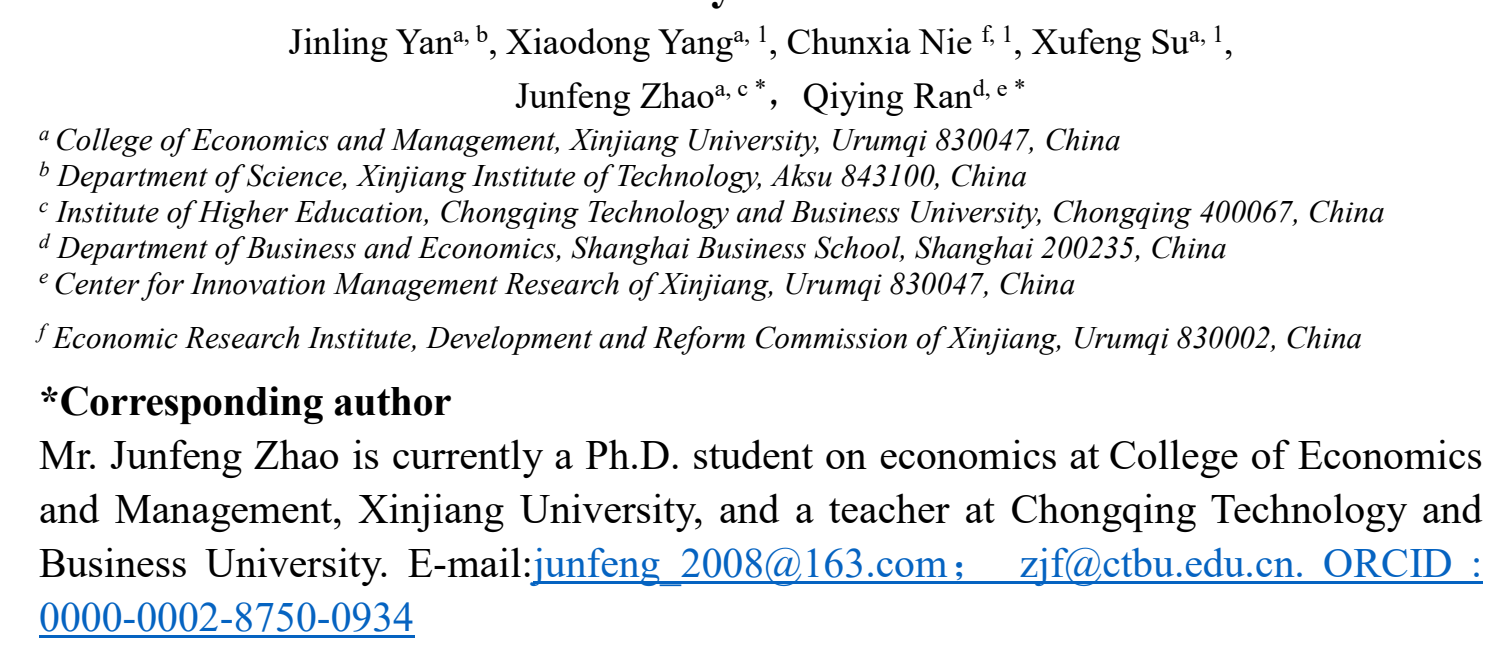

*Corresponding author

Mr. Junfeng Zhao is currently a Ph.D. student on economics at College of Economics and Management, Xinjiang University, and a teacher at Chongqing Technology and Business University. E-mail:junfeng_2008@163.com; zjf@ctbu.edu.cn. ORCID : $\underline{0000-0002-8750-0934}$

Dr. Qiying Ran is currently a full professor at Center for Innovation Management Research of Xinjiang, Xinjiang University, Shanghai Business School. E-mail: ranqiying2021@126.com 


\title{
Does government intervention affect $\mathrm{CO}_{2}$ emission reduction effect of producer services agglomeration? Empirical analysis based on spatial Dubin model and dynamic threshold model
}

\begin{abstract}
Achieving carbon peak and carbon neutrality is an inherent requirement for countries to promote green recovery and transformation of the global economy after the COVID-19 pandemic. As "a smoke-free industry", its agglomeration may have significant impacts on $\mathrm{CO}_{2}$ emission reduction. This study uses nightlight data to calculate the $\mathrm{CO}_{2}$ emissions of 268 cities in China from 2005 to 2017 and then employs dynamic spatial Dubin model and intermediary effect model to explore the impact and transmission mechanism of producer services agglomeration (PSA) on $\mathrm{CO}_{2}$ emissions. Furthermore, the dynamic threshold model is used to analyze the nonlinear characteristics of PSA on $\mathrm{CO}_{2}$ emissions under different degrees of government intervention. The findings indicate that: (1) Generally, China's $\mathrm{CO}_{2}$ emissions are pathdependent in the time dimension, showing a "snowball effect". PSA not only significantly inhibits local $\mathrm{CO}_{2}$ emissions, but also reduces $\mathrm{CO}_{2}$ emissions in adjacent areas through spatial spillover effect; (2) PSA can indirectly curb $\mathrm{CO}_{2}$ emissions through economies of scale, technological innovation and industrial structure upgrading, Heterogeneity analysis shows that there are significant differences in the impact of PSA on $\mathrm{CO}_{2}$ emissions in different regions, time nodes and sub-industries; (3) The impact of PSA on China's $\mathrm{CO}_{2}$ emissions has an obvious double threshold effect under different degree of government intervention. Accordingly, the Chinese government should increase the support for producer services, dynamically adjust industrial policies, take a moderate intervention, and strengthen market-oriented reform to reduce $\mathrm{CO}_{2}$ emissions so that the goal of "carbon peak and carbon neutrality" can be early achieved. Keywords: PSA; Government intervention; China's $\mathrm{CO}_{2}$ emissions; Spatial Dubin model; Dynamic threshold model
\end{abstract}

\section{Introduction}

As a result of the acceleration of industrialization and the combustion of fossil fuels in recent decades, a large number of greenhouse gases represented by $\mathrm{CO}_{2}$ are emitted, resulting in global surface temperatures increasing and more frequent freak weather (Khan et al., 2019) . Currently, the Chinese government is dedicated to carbon emission reduction. The strategic policy of "establishing and improving an economic system for green and low-carbon circular development" has been proposed at the 19th National Congress of the Communist Party of China. In the general debate of the seventy-fifth United Nations General Assembly on September 22, 2020, Chinese President Xi Jinping further claimed that the goal of "carbon peak and carbon neutrality" should be achieved before 2030 and 2060 respectively so as to scale up its Intended Nationally Determined Contributions. Nevertheless, China is proceeding deep into the development of urbanization and industrialization (Jiang and Lin, 2012), and the total carbon emissions have been on the rise. Consequently, China is confronting great pressure on carbon emission reduction (Zhang and $\mathrm{Da}, 2015$ ). Up to now, there is agreement among scholars that the most effective way to reduce carbon emissions is to 
facilitate the upgrading of industrial structure and drastic expansion of tertiary industry (Zhang et al., 2018; Li et al., 2019; Zhang et al.,2020a). It is further proposed at the 19th National Congress of the Communist Party of China that modern service industries should be given priority in the tertiary industry. As an important part of the modern service industries, producer services are "smoke-free industries", which are gradually becoming the key force to promote the industrial transition from manufacturing to producer services (Wu et al., 2013). Statistics show that energy consumed by each unit output of the service industry is no more than $33 \%$ of the secondary industry and $40 \%$ of the primary industry (Tan et al., 2016). At present, the main problem in the traditional manufacturing industry is the neglect of energy conservation and pollution reduction (Ding et al., 2015), while producer services can effectively alleviate "the stubborn diseases" of over-consumption and low output in the manufacturing industry, ultimately reducing global environmental pollution (Yang et al., 2021).

Recently, the service industry has figured prominently in China's national economy. In 2019 , the added value of the service industry increased by $6.9 \%$, accounting for $53.9 \%$ of GDP, of which the added value of the producer service industry accounted for $60 \%$ of the service industry ${ }^{\mathbb{1}}$. With the increasing proportion of the service industry in China's economic development, producer services with the trait of energy conservation and emission reduction have become a significant feature in the new era (Zhao et al., 2021). Appropriate industrial agglomeration can fuel the intensive and large-scale development of agglomeration areas. Therefore, accelerating the development of PSA is not only an important way to alleviate overcapacity and environmental constraints and but also an important strategic measure to finally realize the development of green and low-carbon economy (Yang et al., 2020). However, when industrial agglomeration progresses in certain ways, it will bring about a "crowding effect" (Xi, Y., 2016). Relying too much on the market to regulate the economy, the disadvantages of blindness, spontaneity and lag will be appearing, such as unscientific agglomeration development structure and disgusting competition among enterprises, resulting in a series of environmental problems. Therefore, the government should adopt the appropriate regulation and effective intervention. On the border issue of government intervention, Chinese scholars Lin Yifu and Tian Guoqiang had a debate on it. They maintain that the positive role of local governments in China's economic development cannot be denied, but the negative effect of government "cross-border" behavior on economic development cannot be ignored (Wang and Ju, 2012). In this context, an in-depth study on how PSA affects carbon emissions and how government intervention affects the relationship between them is of great significance both theoretically and practically for early approaching the goal of "carbon peaking and carbon neutralization".

As a result, the possible contributions of this paper include the following aspects: (1) This paper sorts out and analyzes the transmission mechanism of PSA on $\mathrm{CO}_{2}$ emissions, and systematically tests the impact of PSA on $\mathrm{CO}_{2}$ emissions. (2) The spatial Dubin model is used for econometric analysis to effectively reflect the typical characteristics of spatial correlation between $\mathrm{CO}_{2}$ emissions and PSA. (3) The urban panel data is selected as the research sample to effectively reduce the error of estimation

\footnotetext{
Data are calculated according to China Urban Statistical Yearbook
} 
results caused by large spatial scale and internal differences. In addition, as for $\mathrm{CO}_{2}$ emission data calculation, not only energy-related $\mathrm{CO}_{2}$ emissions but also the impact of vegetation carbon sequestration are taken into account, making the data more accurately reflect the actual situation. (4) From the perspective of government intervention, the dynamic threshold model is used to explore the nonlinear characteristics of how government intervention impacts on $\mathrm{CO}_{2}$ reduction effect of PSA, which enriches and develops the research on the influencing factors and mechanism of $\mathrm{CO}_{2}$ emissions.

The rest sections are arranged as follows: The relevant literature is reviewed in Section 2. The theoretical analysis and hypotheses are made in Section 3. The data source and model setting are shown in Section 4. Section 5 illustrates the empirical results and makes discussions. The conclusions and policy implications are followed in Section 7. The whole structure of the research is described in Figure 1.

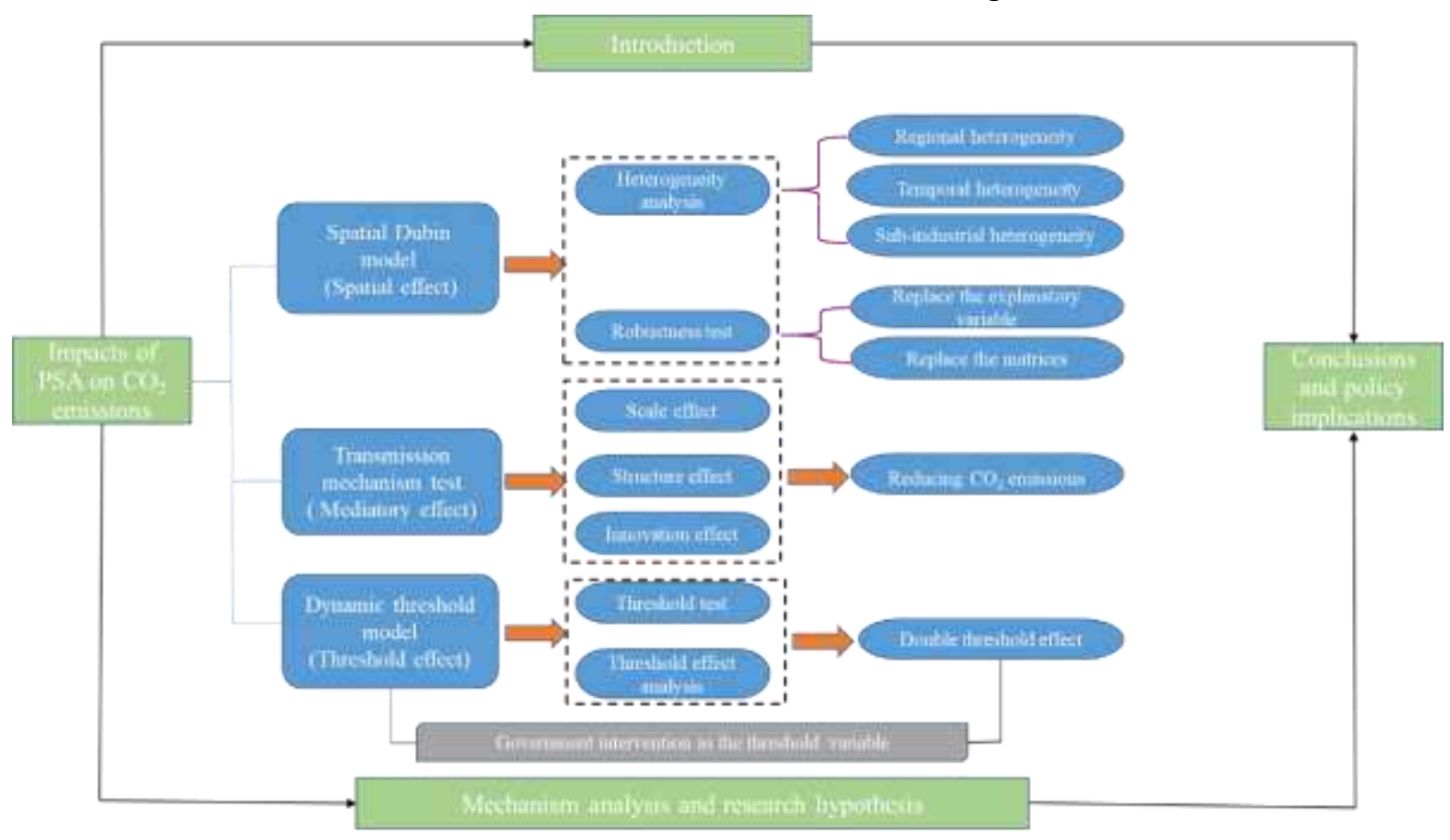

Figure 1. Research structure.

\section{Literature review}

The identification of factors affecting $\mathrm{CO}_{2}$ emissions has always been a research hotspot in academic circles. Up to now, the key influencing factors mainly include economic growth (Govindaraju and Tang, 2013; Kasman and Duman, 2015; Dong et al., 2018), industrial structure (Tian et al., 2019; Pan et al., 2021), technological innovation (Yu and Du, 2019; Wang and Zhu, 2020; Chen and Lee, 2020), financial development (Shahbaz et al., 2013; Zhao and Yang, 2020), urbanization (Martínez-Zarzoso and Maruotti, 2011; Wang et al., 2018a), foreign trade( Hao and Liu, 2015; Huang et al., 2019), industrial agglomeration(Chen et al., 2018; Wu et al., 2021a; Shen \& Peng, 2021). Among these factors, industrial agglomeration is most relevant to this paper, so the literature review of this paper is focusing on the relationship between industrial agglomeration and environmental pollution. Scholars are divided over the relationship between them. Three views are mainly included: first, some scholars hold that pollution emissions are aggravated due to industrial agglomeration through expanding production 
scale (Wen and Liao, 2019) and increasing energy consumption demand (Shen \& Peng, 2021). The second view is that the positive externalities brought by industrial agglomeration will promote the progress and promotion of environmental protection technology, so as to effectively control pollution emissions. Guo et al. (2020) believe that industrial agglomeration can improve the environment, but there are regional heterogeneities. Industrial agglomeration enhances the environmental quality better in the East than in the central and western regions. The third view is that impacts of industrial agglomeration on environmental pollution show nonlinear characteristics. Ren-fa et al. (2015) argue that industrial agglomeration exerts an obvious threshold effect on environmental pollution, that is, if the industrial agglomeration level is below the threshold value, pollution will be intensified, and if it is higher than the value, pollution will be reduced.

At present, few pieces of literature are studying the impact of PSA on $\mathrm{CO}_{2}$ emissions. The literature on the emission reduction effect of industrial agglomeration is mostly discussed from the perspective of manufacturing agglomeration. Most scholars believe that manufacturing agglomeration has a dual effect on pollution emission, which may aggravate pollution emission through expanding production scale(Lan et al., 2021) and increasing energy consumption demand (Cheng, Z., 2016) or reduce pollution emissions through technology spillover, the specialized division of labor and economies of scale (Fang et al., 2020). Wang et al. (2018b) and Yuan et al. (2020) confirm that a significant inverted U-shaped relationship exists between manufacturing agglomeration and environmental pollution. The producer service industry is characterized by knowledge and technology-intensive, low-polluting and low-emitting (Shao et al., 2017). Relying on its agglomeration effect, PSA brings knowledge and technology spillover, so as to alter the rough-oriented pattern of economic growth and reduce $\mathrm{CO}_{2}$ emissions. Therefore, PSA has become a major contributor to realizing green and low-carbon circular economy. With the development of the producer service industry and the enhancement of the pulling effect of the service industry on the national economy, research on the $\mathrm{CO}_{2}$ emission reduction effect of PSA is drawing many scholars' concern at home and abroad in recent years. Some scholars put PSA and $\mathrm{CO}_{2}$ emissions in the same framework for theoretical and empirical research. Zhao et al. (2021) utilized the balanced panel data of China's 30 provinces from 2003 to 2017 to test impacts of PSA on $\mathrm{CO}_{2}$ emissions, finding that PSA can effectively mitigate the $\mathrm{CO}_{2}$ emissions, but there is significant regional heterogeneity; Li et al. (2019) explore the impact of PSA on carbon intensity, concluding that the degree of misallocated resources greatly affects $\mathrm{CO}_{2}$ emission reduction effect of PSA, and there exists a significant double threshold effect.

To sum up, academic circles have systematically studied the impact of industrial agglomeration on environmental pollution, which provides a good research idea for this paper. At present, the systematic research on industrial agglomeration and $\mathrm{CO}_{2}$ emission reduction mostly focuses on the manufacturing industry. The research on the relationship between PSA and $\mathrm{CO}_{2}$ emissions is still at the primary stage, and there is a lack of in-depth exploration on the internal mechanism, heterogeneity and nonlinear characteristics between them. Accordingly, using the panel data of 268 Chinese cities 
over the period from 2005 to 2017, this paper systematically discusses the spatial impact of PSA on $\mathrm{CO}_{2}$ emissions, its internal mechanism and non-linear characteristics by constructing spatial Dubin model, mediatory effect model and dynamic threshold model so that more scientific and targeted policy suggestions can be proposed.

\section{Theoretical analysis and research hypothesis}

\subsection{Analysis of the direct impact of PSA on $\mathrm{CO}_{2}$ emissions}

PSA can adjust market scale and openness, industrial structure and stimulate economic growth by transferring and gathering factors such as population, capital and resources, so as to improve energy efficiency and reduce $\mathrm{CO}_{2}$ emissions (Binbin, $\mathrm{Y}$. 2018; Yang et al., 2020). Compared with industry, producer services have a stronger agglomeration effect and technology-intensive characteristics; PSA can reduce pollution by deepening labor division, extending the industrial value chain and promoting production technology innovation (Francois, J. F., 1990). Under the circumstances of prominent industrial structural contradictions and increasing pressure to conserve energy and reduce emissions, accelerating PSA has become a breakthrough to optimize the industrial structure and reduce $\mathrm{CO}_{2}$ emissions, so as to effectively address the dilemma of "stabilizing growth and promoting emission reduction" (Chen et al., 2020a). According to MAR externality theory (Marshall and Guillebaud, 1961), the agglomeration development of producer services can provide targeted professional services, effectively strengthen the sharing and diffusion of knowledge, information and technology among enterprises, and improve the utilization efficiency of energy factors of enterprises; PSA can further promote industrial enterprises to use information technology, R\&D and design as intermediate inputs for production, and hence ultimately realize energy conservation and emission reduction in the process of industrial production. According to Jacobs' externality theory (Jacobs, J., 2016), the diversified agglomeration of producer services increases the diversity and availability of outsourcing services for pollution emission reduction of industrial enterprises. At the same time, PSA helps to apply new environmental protection technologies and processes to the science and technology industry, improve the energy efficiency of enterprises and achieve pollution emission reduction. Porter's externality theory holds that externality mainly comes from the competitive and professional division of labor in an open environment (Ambec et al., 2013). An open and shared environment is conducive to the formation of a healthy and benign competition mechanism and effectively curbs the spread of opportunism, and thus promotes the fine division of labor of industrial enterprises and a great demand for productive services (Wang et al., 2018b). In this manner, the quality of economic development is improved and pollution emissions are effectively reduced. In addition, as a typical knowledge and technologyintensive industry, the producer services industry gathers a large number of excellent talents, producing a "learning effect"(Zhao et al., 2021). Advanced production technology and innovation information produce a spatial spillover effect with the crossregional flow of personnel (Chen and Lee, 2020). Producer services and the manufacturing industry form a collaborative agglomeration model through the correlation between upstream and downstream industries. This collaborative agglomeration has a significant spatial spillover effect and spatial feedback mechanism. 
The spatial property of urban geographical location determines that the PSA will inevitably produce a spatial spillover effect, thus affecting the surrounding cities (Shao et al., 2017). Information consulting, finance, scientific research and other high-end producer services are mostly located in regional central cities with the characteristics of low transaction frequency and wide service range, which has an obvious spillover impact on pollution emissions in surrounding areas.

Therefore, hypothesis 1 is proposed: PSA can inhibit $\mathrm{CO}_{2}$ emissions and has a spatial spillover effect.

\subsection{Analysis on the impact mechanism of PSA on $\mathrm{CO}_{2}$ emissions}

According to Grossman and Krueger (1995), Brock and Taylor (2005), the main ways to affect environmental pollution include scale effect, structure effect and innovation effect. Therefore, this paper intends to analyze the mechanism of PSA affecting $\mathrm{CO}_{2}$ emissions from the aspects of reducing energy consumption (scale effect), optimizing industrial structure (structure effect), and improving technological innovation (innovation effect).

(1) Scale Effect The spatial agglomeration of producer services can enable infrastructure sharing and intensive utilization of production equipment, which helps manufacturers save production and transaction costs, while the embedding of an effective value chain can reduce resource consumption and $\mathrm{CO}_{2}$ emissions through economies of scale. Specifically, upstream and downstream affiliated enterprises in the same industrial chain gather in the same region, which is conducive to sharing convenient transportation facilities to reduce logistics costs and energy consumption in the transportation process and achieving emission reduction effect. The industrial agglomeration of similar enterprises is easier to form a fully competitive market so as to reduce information asymmetry. Enterprises are forced to reduce prices and save costs, by controlling energy consumption, thus achieving emission reduction effect. Additionally, the centralized discharge and treatment of similar or homogeneous polluting wastes can reduce the environmental treatment cost of enterprises, improve the recycling efficiency of wastes, and minimize the damage to the environment caused by the production.

(2) Structure effect Producer services are an important part of the tertiary industry, and the agglomeration drives the development of the tertiary industry, promotes the optimization and upgrading of industrial structure, and reduces the demand for energy factors and pollutants emissions by improving the efficiency of resource allocation. What's more, PSA and its effective embedding in the manufacturing industry will also help to upgrade the structure of the manufacturing industry and improve production efficiency, achieving pollution reduction. In short, as a modern service industry with low pollution and high added value, PSA can rationally optimize the allocation of resources, effectively improve the industrial structure, and gradually reduce the proportion of the industry, thus reducing $\mathrm{CO}_{2}$ emissions.

(3) Innovation effect Technology spillover can stimulate the innovation potential of enterprises. Enterprises can reduce $\mathrm{CO}_{2}$ emissions by using advanced technology and energy-saving equipment to change the energy consumption structure. Specifically, producer services effectively embed advanced production technology, professional 
theoretical information and cutting-edge innovative ideas into production and manufacturing links in the form of intermediate investment, promote a large number of scientific and technological R \& D and technological competition, so as to improve the product design and scientific management ability, energy utilization efficiency and pollution control level of the manufacturing industry, and finally achieve the effect of energy conservation and emission reduction. Besides manufacturing enterprises use advanced energy-saving equipment and clean energy to replace backward and aging production equipment and fossil energy. These are conducive to reducing $\mathrm{CO}_{2}$ emissions.

Based on this, hypothesis 2 is put forward: PSA indirectly inhibits $\mathrm{CO}_{2}$ emissions through reducing energy consumption, optimizing the industrial structure and improving technological innovation.

\subsection{Analysis on the threshold effect of government intervention}

In China's political system, the promotion of local officials presents a vertical form from top to bottom, so the political promotion of local officials is a direct driving force for the government to intervene in economic development (Wu, et al., 2020a). At the initial stage of the development of producer services, marketization has not been completed, and the decisive role of the market in resource allocation is not prominent. Government intervention has become necessary and important, and its functions encompass four aspects:

First of all, government intervention has improved the market failure caused by externality and information asymmetry at the initial stage of the producer services development. The government conducts rectification through intervention, which reduces market friction and improves the efficiency of resource allocation (Wang et al., 2021). Second, government intervention provides an endogenous impetus for the development of producer services, which is specifically reflected in the government's promotion and improvement of economic development and quality by optimizing the expenditure structure and increasing investment in science, technology and education (Xie et al.,2019); Third, government intervention promotes the rational flow of talents and resources in agglomeration areas of producer services, which will trigger benign competition among governments and help to address problems such as unbalanced development among regions (Sun et al., 2020). However, under the institutional background of fiscal decentralization, the original "GDP-only theory" will lead to serious distortion of resource allocation and imbalance of industrial structure (Li et al, 2021). Specifically, excessive government intervention will lead to a false agglomeration trend in industrial agglomeration areas (Wei and $\mathrm{Wu}, 2021$ ). The cause is that enterprises enter the agglomeration areas to pursue "policy rent" and maximize their interests. The entry of more inefficient enterprises accelerates false agglomeration, resulting in resource waste and mismatch (Hao et al., 2020). For different types of enterprises, the impact of government intervention on resource mismatch also shows heterogeneity (Zhang et al., 2021). For example, in the state-owned economic sector, government intervention can balance the financing cost of enterprises, so as to alleviate the financial resource mismatch, while in the private economic sector, it is just the opposite. Therefore, the different degrees of government intervention will make PSA 
have a different impact on resource allocation, thus differently affecting $\mathrm{CO}_{2}$ emissions.

Accordingly, hypothesis 3 is assumed: Government intervention may have a threshold effect, namely, the appropriate intervention will make PSA inhibit $\mathrm{CO}_{2}$ emissions, whereas excessive intervention will aggravate $\mathrm{CO}_{2}$ emissions.

\section{Model setting and variable selection}

\subsection{Model setting}

\subsubsection{Spatial measurement model setting}

STIRPAT model is one of the important theoretical frameworks to study the influencing factors of environmental pollution (Wu et al., 2021b). Based on the research paradigm of elhorst $\mathrm{J}$, this paper utilizes the general form of STIRPAT model to deeply analyze and discuss the influencing mechanism of PSA on $\mathrm{CO}_{2}$ emissions. Since STIRPAT model can decompose and improve the influencing factors, this paper will further expand it according to EKC hypothesis. In addition, the spatial dependence among variables is not only reflected in the interaction between regions in the current period but also the time inertia due to the endogenous factors of variables (Chen et al, 2019). Accordingly, referring to Wang and Zheng (2021), this paper introduces the dynamic spatial Dubin model into the STIRPAT model to verify the spatial spillover effect of PSA on $\mathrm{CO} 2$ emissions. The model is constructed as follows:

$$
\ln C O_{2 i, t}=\beta_{1} \ln C O_{2 i, t-1}+\rho_{1} W \ln C O_{2 i, t}+\beta_{2} \ln P J+\rho_{2} W \ln P J+\beta_{3} X_{i, t}+\mu_{i}+\lambda_{t}+\varepsilon_{i, t}
$$

Where $i$ is the city; $t$ is time; $\mathrm{CO}_{2}$ represents carbon emissions; $P J$ indicates the agglomeration level of producer services; $X$ consists of control variables; $\beta_{1}$ represents the regression coefficient of the first lag period, which is the impact of $\mathrm{CO} 2$ emissions of the previous period on the current period; $\rho_{1}$ is the spatial lag coefficient, which reflects the impact of surrounding regional $\mathrm{CO}_{2}$ emissions; $\rho_{2}$ represents the spatial lag coefficient of PSA, which reflects the impact of PSA on $\mathrm{CO}_{2}$ emissions in adjacent areas. $W$ represents the spatial weight matrix. In this paper, the reciprocal square weight matrix of distance that can comprehensively reflect the spatial correlation between cities is adopted. The specific element setting method is as follows:

$$
w_{i j}=\left\{\begin{array}{cc}
1 / d_{i j}^{2}, & i \neq j \\
0, & i=j
\end{array}\right.
$$

Diagonal elements of the spatial weight matrix are $0, d_{i j}$ is the geographical distance between the two cities.

\subsubsection{Dynamic threshold model setting}

According to the theoretical research, it is assumed that the impact of PSA on $\mathrm{CO}_{2}$ emissions will show nonlinear characteristics due to different degrees of government intervention. In order to verify this nonlinearity and alleviate the potential endogeneity of the traditional regression model, referring to $\mathrm{Wu}$ et al. (2019), this paper constructs the dynamic threshold effect model: 


$$
\begin{aligned}
\ln C O_{2 i, t}= & \mu_{i}+\ln C O_{2 i, t-1}+\beta \ln P J_{i, t}+\delta X_{i t}+\lambda_{1} \ln P J_{i, t} \times I\left(\ln G O V_{i, t} \leq \gamma_{1}\right) \\
& +\lambda_{2} \ln P J_{i, t} \times I\left(\gamma_{1}<\ln G O V_{i, t} \leq \gamma_{2}\right)+\lambda_{3} \ln P J_{i, t} \times I\left(\ln G O V_{i, t}>\gamma_{2}\right)+\varepsilon_{i, t}
\end{aligned}
$$

Where $\lambda_{1}, \lambda_{2}$ and $\lambda_{3}$ respectively represent the impact coefficient of PSA on $\mathrm{CO}_{2}$ emissions under the different threshold range of government intervention; $\ln G O V$ represents a threshold variable, $\gamma$ is the threshold estimated value, $\gamma_{1}$ and $\gamma_{2}{ }^{2}$ represents the first threshold value and the second threshold value respectively, I represents the indicator function, and the definitions of other variables are the same as in model (1).

\subsection{Variable setting and data source}

4.2.1 Explained variable

Carbon emissions $\left(\mathrm{CO}_{2}\right)$ The available literature on $\mathrm{CO}_{2}$ emission solely focuses on carbon emissions related to energy, while the impact of vegetation carbon sequestration has been ignored. Shan et al. (2016) use the $\mathrm{CO}_{2}$ emission coefficient provided by IPCC and 11 energy such as coal, coke, gas and natural gas to calculate $\mathrm{CO}_{2}$ emissions. In reality, vegetation has a significant impact on $\mathrm{CO}_{2}$ adsorption, accounting for the main part of $\mathrm{CO}_{2}$ emissions from energy consumption (Cox et al., 2000). Ignoring this part of carbon emissions will lead to inaccurate data of $\mathrm{CO}_{2}$ emissions $^{3}$. This paper uses the carbon emission data measured by Chen et al.'s (2020b). The data is currently the most comprehensive urban carbon emissions dataset for cities that have been peer-reviewed and cross-validated in multiple rounds.

\subsubsection{Explanatory variable}

The level of PSA (PJ) Referring to Yuan et al. (2020), this paper uses the location entropy model which can eliminate the endogenous impact caused by regional-scale differences to measure the level of PSA. The greater the location entropy, the more mature the development of the industry in this region, the stronger the agglomeration capacity, and the more scale advantages and comparative advantages compared with other regions in China. The calculation method is as follows:

$$
P J_{i, j}=e_{i, j} / E_{j} / e_{i} / E
$$

Where $e_{i, j}$ refers to the number of employees in $i$ city $j$ industries; $E_{j}$ indicates the total number of employees in the national $j$ industry; $e_{i}$ indicates the total number of employees in all industries in the city $i ; E$ indicates the total number of employees in all industries in the country. Based on the research of Shanzi et al.(2013), the subindustries of the service industry with intermediate demand rate greater than $60 \%$ are

\footnotetext{
(In order to explain the structure of the model easily, it is assumed that there are two effective thresholds, which should be determined according to the estimation results of the model. ${ }^{\circledR}$ This method uses the particle swarm optimization backpropagation (PSO-BP) algorithm to unify the scale of DMSP / OLS and NPP / viirs images from 1997 to 2017 and then utilize the PSO-BP algorithm to reduce the size of energy carbon emission based on Provincial night lighting data.
} 
defined as producer services, including "transportation, warehousing, post and telecommunications", "leasing and commercial services", "wholesale and retail trade", "finance", "information transmission, computer services and software" "Scientific research, technical services and geological exploration".

\subsubsection{Threshold variable}

Government intervention (GOV) Referring to Ma et al. (2021), this paper uses the ratio of local fiscal expenditure to GDP to measure the level of government intervention. The greater the ratio, the lower the marketization level and the more government intervention.

4.2.4 Control variables: (1) Population density (POP) It can mirror the relationship between population and space in a region. The larger the population density, the more environmental and social problems it will bring, which will also affect $\mathrm{CO} 2$ emissions. (2) Foreign direct investment (FDI) The impact of FDI on environmental pollution in host countries can be summarized into two kinds: the positive effect of improving environment pollution by promoting technological innovation or a "pollution shelter" effect by transfer of high-polluting industries. FDI is reflected by the proportion of the annual actual amount of foreign investment in GDP. (3) Human capital (HUM) The improvement of human capital is conducive to the development of local energy conservation and emission reduction technologies. The number of people with bachelor's degrees or above among the employed population in each city is used as the proxy variable of human capital level. (4) Financial development (FIN) The financial system with a good financial development level can transfer funds from inefficient departments to efficient departments, so as to enhance the efficiency of the overall economic system. It is expressed by the proportion of the year-end deposit and loan balance of financial institutions in GDP.

\subsubsection{Data sources and descriptive statistics of variables}

Given the availability of data, this paper samples 268 cities in China from 2005 to 2017. The original data of each indicator comes from the China Urban Statistical Yearbook, China Environmental Yearbook, the official website of the National Bureau of Statistics, the official website of provincial and municipal statistical bureaus and the EPS database from 2004 to 2019. Some missing data are supplemented by interpolation. The descriptive statistics of variables are shown in Table 1.

Table 1. Variable description statistics.

\begin{tabular}{llllll}
\hline Variable & Obs & Mean & Std.Dev & Min & Max \\
\hline $\operatorname{lnCO} 2$ & 3484 & 2.9813 & 0.7729 & 0.5443 & 5.6283 \\
$\operatorname{lnPJ}$ & 3484 & -0.1654 & 0.3124 & -2.0103 & 1.1535 \\
$\operatorname{lnPOP}$ & 3484 & 5.7457 & 0.9035 & 1.5475 & 7.8866 \\
$\operatorname{lnFDI}$ & 3484 & 2.635 & 1.4353 & -5.8385 & 6.8062 \\
$\ln \mathrm{HUM}$ & 3484 & -0.1641 & 1.3901 & -36.84 & 2.6503 \\
$\operatorname{lnFIN}$ & 3484 & 1.3029 & 0.6069 & -4.2008 & 4.0508 \\
$\ln R G D P$ & 3484 & 10.3021 & 0.7466 & 8.0591 & 15.6752 \\
$\operatorname{lnIND}$ & 3484 & -0.1814 & 0.3426 & -1.8532 & 1.0778 \\
$\operatorname{lnINNOV}$ & 3484 & 6.4182 & 1.8617 & 0 & 11.8428 \\
\hline
\end{tabular}




\section{Empirical results analysis and discussion}

Based on the externality of PSA, a spatial econometric model is employed to investigate the impact of PSA on $\mathrm{CO}_{2}$ emissions and the spatial spillover effect.

\subsection{Analysis of spatial effect results}

\subsubsection{Spatial autocorrelation analysis}

The spatial correlation of variables should be tested first. Moran's I is used to examine the spatial correlation of carbon emissions. The results in Table 2 reveal that the Moran index of $\mathrm{CO}_{2}$ emissions fluctuated between 0.043-0.0447 from 2005 to 2017, indicating that Chia's $\mathrm{CO}_{2}$ emissions show a significant spatial positive correlation, further verifying that it is appropriate to use the spatial measurement model for empirical test. In order to further present the spatial agglomeration characteristics of $\mathrm{CO}_{2}$ emission levels, the local Moran scatter diagrams in 2005 and 2017 are presented in Figure 2. It can be seen that the scatter points are mainly distributed in the first quadrant (high-high agglomeration) and the third quadrant (low-low agglomeration), and as time goes on, the concentration trend of $\mathrm{CO}_{2}$ emissions mainly moves to the first quadrant (high-high agglomeration) and the second quadrant (low-high agglomeration). Overall, there is a significant spatial correlation between $\mathrm{CO}_{2}$ emission levels in local cities.

Table 2. Moran index of $\mathrm{CO}_{2}$ emissions from 2005 to 2017

\begin{tabular}{lccccccc}
\hline Year & 2005 & 2006 & 2007 & 2008 & 2009 & 2010 & 2011 \\
\hline Moran's I & $0.047 * * *$ & $0.045^{* * *}$ & $0.047 * * *$ & $0.049 * * *$ & $0.046 * * *$ & $0.046^{* * *}$ & $0.047^{* * *}$ \\
Z-Value & 7.371 & 7.071 & 7.276 & 7.524 & 7.19 & 7.137 & 7.171 \\
\hline Year & 2012 & 2013 & 2014 & 2015 & 2016 & 2017 & \\
\hline Moran's I & $0.047 * * *$ & $0.045^{* * *}$ & $0.044 * * *$ & $0.047 * * *$ & $0.046 * * *$ & $0.043 * * *$ & \\
Z-Value & 7.17 & 6.802 & 6.734 & 7.061 & 6.997 & 6.604 & \\
\hline
\end{tabular}

Note: “***” stands for significance at $1 \%$ level.
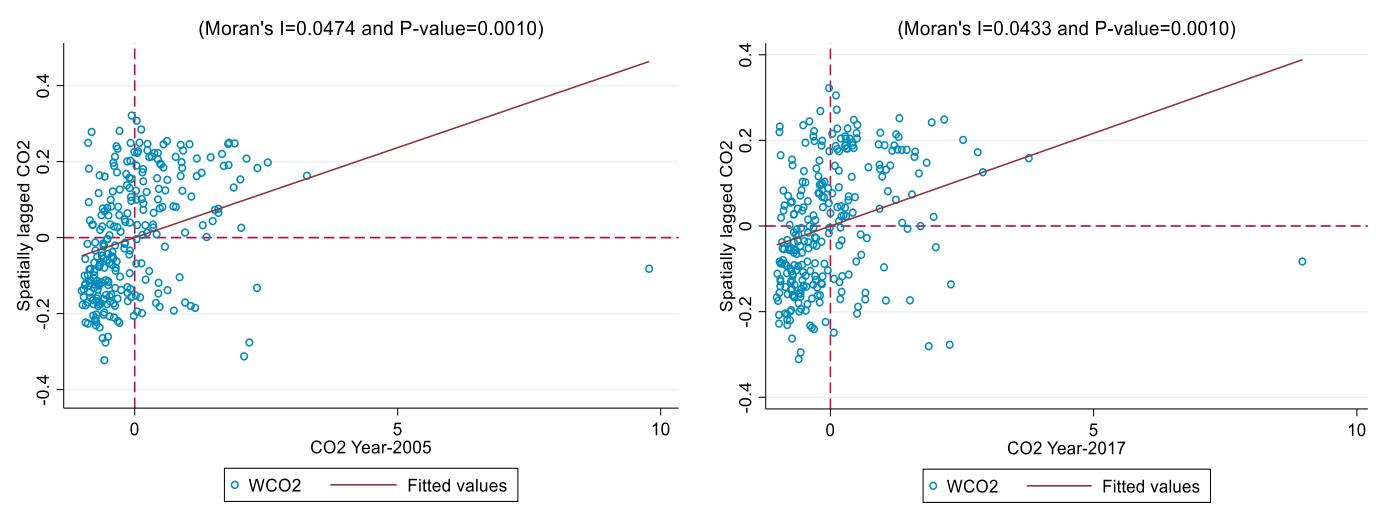

Figure 2. Scatter diagram of Moran's I index of $\mathrm{CO}_{2}$ emissions in China

\subsubsection{Selection and test of spatial metrology model}

Considering the spatial correlation of $\mathrm{CO}_{2}$ emissions, this paper preliminarily sets the model as the bidirectional fixed spatial Dubin model (SDM) and carries out a correlation test. According to the test results in Table 3, the bidirectional fixed spatial Dubin model (SDM) is appropriate.

Table 3. Test results of spatial econometric model selection. 


\begin{tabular}{llllcl}
\hline Index & Value & p-value & Index & Value & p-value \\
\hline LM-lag & $620.069^{* * * *}$ & 0.000 & LM-error & $706.894^{* * * *}$ & 0.000 \\
Robust LM-lag & $4.105^{* *}$ & 0.043 & Robust LM-error & $90.929^{* * *}$ & 0.000 \\
LR-lag & $22.53^{* * *}$ & 0.002 & LR-error & $23.74^{* * *}$ & 0.001 \\
WALD-SAR & $22.55^{* * *}$ & 0.002 & WALD-SEM & $23.69^{* * *}$ & 0.001 \\
Hausman & $4.92^{* * *}$ & 0.002 & & & \\
\hline
\end{tabular}

Note: “**” and “***” stand for significance at 5\% and $1 \%$ levels, respectively.

5.1.3 Analysis and discussion of benchmark regression

In order to eliminate the endogeneity in spatial regression, the estimation result of the system generalized estimation method (SYS-GMM) is introduced (Wu et al, 2020b). In addition, for checking the robustness of the estimation results, the estimation results of SAR and SEM are also listed. The estimation results in Table 4 show that the magnitude, direction and significance of the estimated coefficients of the core variables in all models are consistent, indicating that the estimations are scientific and robust. The following mainly analyzes the spatiotemporal fixed effect results of the dynamic spatial Dubin model. From the perspective of the time dimension, the regression coefficient of $\mathrm{CO}_{2}$ emissions in the first lag phase $\left(\mathrm{CO}_{2 t-1}\right)$ is positive at the $1 \%$ significance level, indicating that China's $\mathrm{CO}_{2}$ emissions have significant "time inertia", that is, if the $\mathrm{CO}_{2}$ emissions in the current period are at a high level, the $\mathrm{CO}_{2}$ emissions level in the next phase may go on increasing, showing the "snowball effect". The reason may be that the adjustment of some economic policies, such as the optimization of industrial structure, population agglomeration, technological progress has a time lag ( $\mathrm{Li}$ et al., 2017), resulting in the lag of the change in $\mathrm{CO}_{2}$ emissions. From the estimation results of explanatory variables, the direct effect and spatial spillover of PSA on $\mathrm{CO}_{2}$ emissions are significantly negative, indicating that PSA has an obvious inhibitory effect on $\mathrm{CO}_{2}$ emissions in the local and its adjacent areas. The possible reason is that PSA makes the internal division of labor tend to be more reasonable and the production more efficient, which improves the utilization efficiency of energy and promotes the manufacturing industry to accelerate the $\mathrm{R} \& \mathrm{D}$ of clean technologies and extend the industrial chain (Zhao et al., 2021). In addition, it can also provide diversified and complementary technical services for the manufacturing industry of the city and adjacent cities, and contribute to the technological innovation of the manufacturing industry, thus significantly inhibiting $\mathrm{CO}_{2}$ emissions in the local and adjacent cities (Liu et al., 2018). In terms of control variables, population density is positively significant. The reason is that too many people will consume more energy, leading to an increase in $\mathrm{CO}_{2}$ emissions. The coefficient of FDI is significantly negative, implying that FDI, as a strategic means of the market for technology in China, significantly improves the production efficiency of the manufacturing industry through the technology spillover effect (Dong et al., 2019), which is conducive to $\mathrm{CO}_{2}$ emission reduction. The coefficient of human capital is significantly negative, mainly because the improvement of human capital level can make the spillover effect of technology and knowledge give full play, bring advanced technology and management experiences to enterprises, 
improve production efficiency and reduce $\mathrm{CO}_{2}$ emissions (Abel and Deitz, 2011). The coefficient of financial development level (FIN) is significantly negative, indicating that the development of the financial industry can optimize the allocation of financial resources, provide financial support for technological innovation of industries and enterprises, and help to promote the progress of environmental protection technology (Wang and Tan, 2021), so as to reduce $\mathrm{CO}_{2}$ emissions.

Table 4. Benchmark regression estimation results

\begin{tabular}{|c|c|c|c|c|}
\hline \multirow{2}{*}{ Variable } & (1) & (2) & (3) & (4) \\
\hline & SYS-GMM & SAR & SEM & SDM \\
\hline \multirow[t]{2}{*}{ L. $\operatorname{lnCO}{ }_{2}$} & $0.8032^{* * *}$ & $0.7736^{* * * *}$ & & $0.7779^{* * * *}$ \\
\hline & $(63.74)$ & (34.69) & & (35.77) \\
\hline \multirow[t]{2}{*}{$\ln \mathrm{PJ}$} & $-0.264^{* * *}$ & $-0.8146^{* * *}$ & $-0.8321^{* * * *}$ & $-0.6716^{* *}$ \\
\hline & $(-20.74)$ & $(-3.28)$ & $(-3.17)$ & $(-2.44)$ \\
\hline \multirow[t]{2}{*}{$\ln \mathrm{POP}$} & $0.1467^{* * *}$ & $0.0867^{* *}$ & $0.0889^{*}$ & $0.0204^{* *}$ \\
\hline & $(54.77)$ & $(0.82)$ & $(0.75)$ & $(0.15)$ \\
\hline \multirow[t]{2}{*}{$\operatorname{lnFDI}$} & $-0.0148^{* * *}$ & $-0.2132^{* *}$ & $-0.2598^{* * *}$ & $-0.3349^{* *}$ \\
\hline & $(-3.35)$ & $(-2.34)$ & $(-2.74)$ & $(-3.46)$ \\
\hline \multirow[t]{2}{*}{ lnHUM } & $-0.0659 * * *$ & $-0.1197 * *$ & $-0.1047 * *$ & $-0.0582 *$ \\
\hline & $(-3.56)$ & $(-1.96)$ & $(-1.63)$ & $(-0.87)$ \\
\hline \multirow[t]{2}{*}{$\ln F I N$} & $-0.4593^{* * *}$ & $0.1388^{*}$ & 0.169 & $-1.6576^{* *}$ \\
\hline & $(-13.18)$ & $(1.11)$ & (1.32) & $(-1.65)$ \\
\hline \multirow[t]{2}{*}{$\mathrm{W} * \ln \mathrm{PJ}$} & & & & $-0.4538^{* *}$ \\
\hline & & & & $(0.26)$ \\
\hline AR (1) & $-3.94[0.000]$ & & & \\
\hline $\mathrm{AR}$ (2) & $0.64[0.520]$ & & & \\
\hline Hansen & $267.27[0.99]$ & & & \\
\hline \multirow[t]{2}{*}{$\rho$ or $\lambda$} & & $0.8583^{* * *}$ & $0.8591^{* * *}$ & $0.8377^{* * * *}$ \\
\hline & & $(23.41)$ & $(25.53)$ & $(20.21)$ \\
\hline $\mathrm{R}^{2}$ & & 0.324 & 0.205 & 0.587 \\
\hline
\end{tabular}

495

496

497

498

499

500

501

502

503

504

505

506

507

508

509

Note: “*”, “**” and “***” stand for significance at 10\%, 5\% and 1\% levels, respectively. Z-values are in () and P-values are in [].

\subsubsection{Heterogeneity analysis and discussion}

Considering the differences in regions, time nodes and sub-industries, this paper further explores the differential impact of PSA on $\mathrm{CO}_{2}$ emissions.

(1) Regional heterogeneity 268 cities are divided into two sample groups for regression: the East (95) and the central and Western (173). Columns (1) and (2) in Table 5 show that impacts of PSA on $\mathrm{CO}_{2}$ emissions vary in the eastern, and central and western regions. The possible reasons are that most cities in the eastern region have entered the period of urbanization, the industrial chain has extended to the high-end producer service industry with innovative elements such as technology, information and knowledge, the spillover of technology and knowledge has been brought into play, and its agglomeration has significantly inhibited $\mathrm{CO}_{2}$ emissions, whereas most of the neighboring areas are at the middle and low end of the industrial value chain. Due to the mismatch of industrial structure and other reasons, the spillover effect may not be 
significant in the neighboring areas. Most cities in the central and western regions are in the middle and late stages of industrialization. Producer services are mainly at the middle and low end of the value chain with low technology content. In order to promote their development, a large amount of energy is invested, which will aggravate $\mathrm{CO}_{2}$ emissions.

(2) Temporal heterogeneity The State Council issued the Guiding Opinions on Accelerating the Development of Producer Services and Promoting the Adjustment and Upgrading of Industrial Structure in 2014 (hereinafter referred to as Opinion). In order to further explore the divergent impact of PSA on $\mathrm{CO}_{2}$ emissions before and after the implementation of the policy, and clarify the direction and focus of the development of producer services in the future, based on the issuing time of the Opinion, the samples are divided into two stages: 2005-2013 and 2014-2018. The results in columns (3) and (4) in Table 5 show that the impact of PSA on $\mathrm{CO}_{2}$ emissions has changed from being insignificant in the previous stage to significantly inhibit. The reason is that the Opinions have made a clear positioning for producer services, and provided a policy basis for the development of producer services to promote the adjustment and upgrading of industrial structure, which clarifies the development orientation and task of producer services and lead them to develop green and environmental protection industry. Therefore, after the promulgation of the Opinions, PSA is conducive to $\mathrm{CO}_{2}$ emission reduction.

(3) Industry heterogeneity The agglomeration of sub-industries of producer services has different impacts on $\mathrm{CO}_{2}$ emissions. The possible reasons are that "wholesale and retail trade", "transportation, warehousing, post and telecommunications" and "leasing and commercial services" are at the low end of the value chain and their agglomeration and development will bring about some problems such as urban congestion, repeated construction of roads, tracks and other infrastructure, which will aggravate the $\mathrm{CO}_{2}$ emissions of local and surrounding cities (Lin and Chen, 2021); On the contrary, as for the high-end producer services at the top of the industrial chain such as "information transmission, computer services and software", "finance" and "Scientific research, technical services and geological exploration", which have the advantages of technology driving and knowledge relevance, their agglomeration and development can greatly promote technology diffusion and innovation along with productivity in the whole region (Iammarin et al., 2019). Therefore, it will not only reduce local $\mathrm{CO}_{2}$ emissions but also have a learning and demonstrating effect on the surrounding areas, bringing about a positive technology spillover effect, which will contribute to the $\mathrm{CO}_{2}$ emission reduction in the surrounding areas.

Table 5. Estimation results of regional and temporal heterogeneity

\begin{tabular}{lcccc}
\hline & \multicolumn{2}{c}{ Regional heterogeneity } & \multicolumn{2}{c}{ Temporal heterogeneity } \\
\cline { 2 - 5 } Variable & $(1)$ & $(2)$ & $(3)$ & $(4)$ \\
\cline { 2 - 5 } & Eastern Region & Central and Western & $2005-2013$ & $2014-2017$ \\
\hline $\operatorname{lnPJ}$ & Region & 0.4802 & $-0.9053^{* * *}$ \\
& $-2.5549^{* *}$ & $1.4837^{* * *}$ & $(0.73)$ & $(-2.87)$ \\
$\mathrm{W} * \ln \mathrm{NJ}$ & $(-2.24)$ & $(3.07)$ & $-13.195^{*}$ & $-9.63^{* * *}$
\end{tabular}




\begin{tabular}{lcccc} 
& $(0.59)$ & $(2.53)$ & $(-1.65)$ & $(-2.87)$ \\
Control & Yes & Yes & Yes & Yes \\
Time-fixed & Yes & Yes & Yes & Yes \\
City-fixed & Yes & Yes & Yes & Yes \\
& $0.4974^{* * *}$ & & & \\
$\rho$ & $(5.82)$ & $0.8260^{* *}$ & $0.8480^{* * *}$ & $0.8340^{* * * *}$ \\
$\mathrm{R}^{2}$ & 0.632 & $(18.5)$ & $(18.08)$ & $(10.96)$ \\
\hline
\end{tabular}

547

Note: “*”, “**” and “***” stand for significance at 10\%, 5\% and 1\% levels, respectively. Z-values are in ().

Table 6. Estimation results of industry heterogeneity

\begin{tabular}{lcccccc}
\hline \multirow{2}{*}{ Variable } & \multicolumn{7}{c}{ Sub-industry ${ }^{(4)}$} \\
\cline { 2 - 7 } & WRT & TWPT & ITCSS & FIN & LCS & SRTSGE \\
\hline \multirow{2}{*}{$\ln$ PJ } & $0.4215^{* * *}$ & $0.0046^{* * *}$ & $-0.7793^{* * *}$ & $-0.4201^{* * *}$ & $0.6706^{* * *}$ & $-0.2504 * * *$ \\
& $(3.14)$ & $(0.03)$ & $(-2.71)$ & $(-3.14)$ & $(2.97)$ & $(-0.8)$ \\
W*lnPJ & -0.5879 & $5.2577 * * *$ & $-1.748^{*}$ & -0.9902 & 0.1056 & $-6.9024 *$ \\
& $(-0.56)$ & $(3.41)$ & $(-0.6)$ & $(-0.79)$ & $(0.05)$ & $(-1.92)$ \\
Control & Yes & Yes & Yes & Yes & Yes & Yes \\
Time-fixed & Yes & Yes & Yes & Yes & Yes & Yes \\
City-fixed & Yes & Yes & Yes & Yes & Yes & Yes \\
$\rho$ & $0.838^{* * *}$ & $0.8269^{* * *}$ & $0.8373 * * *$ & $0.838^{* * *}$ & $0.8382^{* * *}$ & $0.8374 * * *$ \\
& $(20.24)$ & $(18.84)$ & $(20.16)$ & $(20.24)$ & $(20.27)$ & $(20.16)$ \\
$\mathrm{R}^{2}$ & 0.37 & 0.511 & 0.25 & 0.36 & 0.46 & 0.38 \\
\hline
\end{tabular}

Note: “*” and "***" stand for significance at $10 \%$ and $1 \%$ levels, respectively. Z-values are in ().

\subsubsection{Robustness test}

(1) Replace the explanatory variable

Referring to the research of Liu et al. (2020), this paper uses employment density (ED) as an alternative index to reflect the agglomeration degree of producer services. ED measures the spatial agglomeration degree of an industry by calculating the number of employees per unit area of industry. The greater the density, the higher the regional concentration of the industry. The calculation formula is as follows:

$$
E D_{i, t}=x_{i, t} / \text { area }_{i}
$$

Where $i$ and $t$ represent the city and year respectively, ED refers to the employment density of an industry, $x$ refers to the number of employees in an industry, area refers to the land area of the administrative region of the city.

(2) Replace the matrices

\footnotetext{
(4) The initials of sub-industries "WRT", "TWPT", "ITCSS", "FIN", "LCS” and "SRTSGE" stand for "wholesale and retail trade", "transportation, warehousing, post and telecommunications", "information transmission, computer services and software" , "finance", "leasing and commercial services", and "Scientific research, technical services and geological exploration", respectively.
} 
In the econometric model, the weight matrix is exogenous. This paper uses the adjacency weight matrix and economic distance weight matrix to regress the spatial Dubin model again to confirm the robustness of the results.

(1) Adjacency weight matrix $\left(W^{c}\right)$. If two cities are geographically adjacent, $W_{i j}^{c}=1,(i \neq j) ;$ otherwise, $W_{i j}^{c}=1,(i=j)$

(2) Economic distance weight matrix $\left(W^{e}\right)$. The weight setting adopts the reciprocal of the absolute value of the economic development level gap between the two cities $W_{i j}^{e}=1 /\left|e_{i}-\overline{e_{j}}\right|,(i \neq j), W_{i j}^{e}=0,(i=j)$. Where $\bar{e}_{i}$ represents the regional average GDP corrected by the GDP deflator.

It can be seen in Table 7 that either replacing the explanatory variable or the matrices, the symbols, coefficients, and significance of the core variables are consistent with the previous estimations in Table 4, which further proves that the setting of the model and the regression results are reliable and robust.

Table 7. Estimation results of the robustness test

\begin{tabular}{|c|c|c|c|c|}
\hline \multirow{3}{*}{ Variable } & \multicolumn{2}{|c|}{ ED as the explanatory } & $W^{c}$ and $W^{e}$ & \multirow{2}{*}{$\frac{\text { as matrices }}{(4)}$} \\
\hline & (1) & (2) & (3) & \\
\hline & SYS-GMM & SDM & $W^{c}$ & $W^{e}$ \\
\hline \multirow[t]{2}{*}{ L.GTFP } & $0.8054^{* * *}$ & $0.7756^{* * * *}$ & $0.8788^{* * * *}$ & $0.8123^{* * * *}$ \\
\hline & $(4.221)$ & $(3.521)$ & $(3.756)$ & (3.625) \\
\hline \multirow[t]{2}{*}{$\ln \mathrm{PJ}$} & $-0.2546^{* * *}$ & $-0.7885^{* *}$ & $-0.8254^{* * *}$ & $-0.9182^{* * * *}$ \\
\hline & $(-40.74)$ & $(-2.75)$ & $(-3.14)$ & $(-3.58)$ \\
\hline \multirow[t]{2}{*}{$\mathrm{W}^{*} \ln \mathrm{PJ}$} & & $-1.7818^{* *}$ & $-6.5222^{* *}$ & $-1.3646^{* *}$ \\
\hline & & $(-0.61)$ & $(-1.38)$ & $(-1.98)$ \\
\hline Control & Yes & Yes & Yes & Yes \\
\hline Time-fixed & Yes & Yes & Yes & Yes \\
\hline City-Fixed & Yes & Yes & Yes & Yes \\
\hline $\operatorname{AR}(1) / \operatorname{AR}(2)$ & {$[0.000] /[0.5312]$} & & & \\
\hline Hansen & [0.999] & & & \\
\hline \multirow[t]{2}{*}{$\rho$} & & $0.8403^{* *}$ & $0.1745^{* * *}$ & $0.158^{* * *}$ \\
\hline & & $(24.15)$ & $(43.29)$ & $(43.73)$ \\
\hline $\mathrm{R}^{2}$ & & 0.4235 & 0.262 & 0.39 \\
\hline \multicolumn{5}{|c|}{$\begin{array}{l}\text { Note: "*** and "****" stand for significance at } 5 \% \text { and } \\
\text { and P-values are in []. }\end{array}$} \\
\hline \multicolumn{5}{|c|}{ 5.2 Transmission mechanism test and discussion } \\
\hline \multicolumn{5}{|c|}{ According to the above regression results, PSA has an inhibitory effect on urban } \\
\hline
\end{tabular}


Among them, scale effect is measured by per capita GDP; Structure effect is measured by the proportion of tertiary industry in the secondary industry; Technical effect is expressed in the number of patent applications authorized. Referring to Baron and Kenny et al. (1986), three regression equations are constructed for mediating effect test.

$$
\ln C O_{2 i t}=\alpha_{0}+\alpha_{1} \ln P J+\alpha_{2} X_{i t}+\mu_{i t}
$$

$$
M_{i t}=\beta_{0}+\beta_{1} \ln P J+\beta_{2} X_{i t}+\mu_{i t}
$$

$$
\ln C O_{2 i t}=\theta_{0}+\theta_{1} \ln P J+\theta_{2} M_{i t}+\theta_{3} X_{i t}+\mu_{i t}
$$

Where $X$ represents a set of control variables; $M$ are possible intermediary variables, including per capita (RGDP), industrial structure (IND) and technological innovation (INNOV).

Columns (1) - (3) in Table 8 show the impacts of PSA on $\mathrm{CO}_{2}$ emissions when economies of scale are taken as the intermediary variable. Column (1) shows that the total effect of PSA on $\mathrm{CO}_{2}$ emissions is -5.765, which is significant at the level of $1 \%$. Column (2) shows the regression of PSA to urban economies of scale. The coefficient of economies of scale is significantly positive at the level of $1 \%$, indicating that PSA significantly promotes urban economies of scale. Column (3) shows that the $\mathrm{CO}_{2}$ emission level is affected by economies of scale and PSA. All coefficients are significantly negative at the level of $1 \%$, and the absolute value of the coefficient $\theta_{1}$

(- 5.5026) of PSA is less than the absolute value of $\alpha_{1}(-5.765)$, indicating that PSA can indirectly inhibit the $\mathrm{CO}_{2}$ emission level by promoting urban economies of scale, Sobel test and bootstrap test are significant at the level of 5\%, which also verifies that the intermediary effect exists significantly, and the proportion of intermediary effect in the total effect is $16.54 \%$. Similar analyses are made when industrial structure and technological innovation are intermediary variables. The results show that the intermediary effect of industrial structure accounts for $13.47 \%$ of the total effect, and that of technological innovation accounts for $44.52 \%$ of the total effect. The hypothesis $\mathrm{H} 2$ is verified. Comparing the three intermediary effects, the technological innovation effect is leading first, followed by economies of scale and industrial structure. This implies that PSA, especially high-end PSA, stimulates the innovation potential of enterprises through technology spillover. Enterprises are more inclined to use advanced technology and energy-saving equipment to change the energy consumption structure, and thus reduce $\mathrm{CO}_{2}$ emissions. Besides, the inhibition of scale effect and structure effect is limited. The reason is that currently, China's economy is experiencing rapid development, the secondary industry is still in an important position and the proportion in the industrial structure may be relatively higher. Only the "green" upgrading of the industrial structure can effectively curb $\mathrm{CO}_{2}$ emissions.

Table 8. Test results of the transmission mechanism

\begin{tabular}{cccc}
\hline $\begin{array}{c}\text { Intermediary } \\
\text { Effect }\end{array}$ & Scale effect & Structure effect & Innovation effect \\
\cline { 2 - 3 }
\end{tabular}




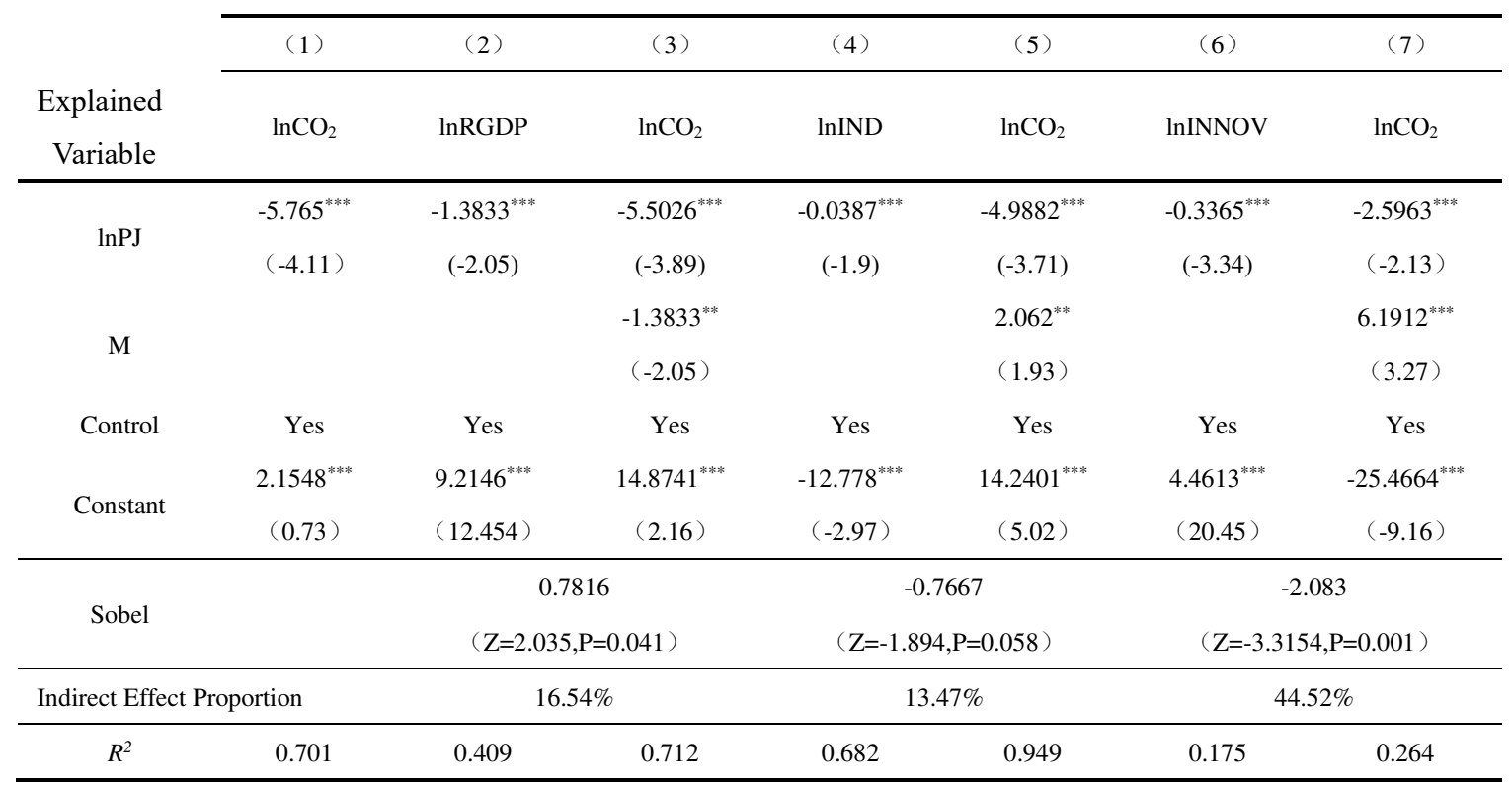

Note: "**" and "***" stand for significance at 5\% and $1 \%$ levels, respectively. Z-values are in ().

\subsection{Threshold effect analysis and discussion}

According to the previous theoretical analysis, the impact of PSA on $\mathrm{CO}_{2}$ emissions may have nonlinear characteristics due to different degrees of government intervention. Therefore, the dynamic threshold effect with government intervention as the threshold is analyzed.

\subsubsection{Validity test of the threshold value}

The first step is to estimate the dynamic threshold panel model for testing its effectiveness through threshold value. The estimation results are as follows:

Table 9. Threshold estimation and test results

\begin{tabular}{ccccccc} 
Model & F-statistics & P-value & BS number & \multicolumn{3}{c}{ Critical value } \\
\cline { 5 - 6 } & & & & & & \\
\cline { 4 - 5 } Single threshold test & 69.05 & 0.000 & 300 & 37.47 & 30.64 & 26.99 \\
Double threshold test & 32.78 & 0.003 & 300 & 27.60 & 23.89 & 21.11 \\
Triple threshold test & 16.64 & 0.5833 & 300 & 36.13 & 32.29 & 30.04 \\
\hline
\end{tabular}

As shown in Table 9, single and double thresholds are significant at the $1 \%$ level, but the triple threshold failed the test. The results indicate that government intervention has a double threshold effect. Table 10 presents the threshold estimations and confidence intervals of the double threshold model.

Table 10. Threshold estimations and confidence intervals

$95 \%$ confidence intervals

Threshold value $\gamma_{1}$

Threshold value $\gamma_{2}$

0.8210

[0.8067,0.8267] 
degrees of government intervention: when the level of government intervention is below the threshold value of 0.1719 , the coefficient of PSA is -0.4934 and significant at $1 \%$ level, indicating that PSA can significantly inhibit $\mathrm{CO}_{2}$ emissions; When the government intervention level is beyond the threshold value of 0.1719 , the coefficient of PSA is 0.1898 and significant at $1 \%$ lever, indicating that PSA significantly promotes $\mathrm{CO}_{2}$ emissions, but the coefficient is smaller and the promotion effect is weaker; When the level of government intervention reaches 0.8210 , the impact of PSA on $\mathrm{CO}_{2}$ emissions is significantly positive with a coefficient of 0.5816 , which is as 3.06 times as that of the previous threshold, indicating that excessive government intervention will greatly aggravate $\mathrm{CO}_{2}$ emissions. The possible reasons are that government intervention has a significant threshold effect, and the resource allocation effect of PSA is affected by government intervention to a certain extent. For example, in terms of talent introduction and investment attraction, the government can provide a series of subsidies and preferential policies, which will have a positive impact on the factor market and resource allocation. Therefore, in the process of industrial agglomeration affecting $\mathrm{CO}_{2}$ emissions, Market forces usually play a regulatory role, but when marketization has not been completed, the market fails to play the decisive role in resource allocation (Zhang et al., 2020b). Under the background of optimization and upgrading of industrial structure, China's economic development and transformation are currently at a crucial stage. The degree of marketization varies greatly in different regions. Imperfect marketization mechanism usually leads to problems such as weak consciousness of property rights protection, closed institutional environment, and even corruption. Therefore, when there is an excessive agglomeration of producer services, the government should timely guide by taking macro-intervention to adjust the industrial agglomeration to the process of coordinated development with resources and environment. As a result, the agglomeration effect may be affected by government intervention. Moderate government intervention can reduce energy consumption and achieve the effect of $\mathrm{CO}_{2}$ emission reduction by optimizing resource allocation. At the same time, the government is the "night watchman" for industrial development and environmental quality improvement, which affects industrial agglomeration and diffusion. PSA reduces $\mathrm{CO}_{2}$ emissions by promoting the flow of production factors to low-cost and resource-saving sectors, selecting the best location for development, realizing the optimal allocation of production factors, changing resource consumption intensity and energy conversion. However, excessive government intervention will lead to distortion in factor markets and subsidies (Lin and Chen, 2018). In addition, local governments stimulate the economy by using various policy means to promote industries that do not have comparative advantages, thus distorting factor prices and causing efficiency losses. In short, moderate government intervention is not only conducive to reducing the risk cost of technological innovation but also to alleviating market failure. Excessive government intervention may cause the misallocation of the resources and not be conducive to the operation of market economic mechanisms, leading to the increase of $\mathrm{CO}_{2}$ emissions.

Table 11. Threshold effect estimation results.

\begin{tabular}{llll}
\hline Explained variable & Elasticity coefficient & T-value & P-value
\end{tabular}




\begin{tabular}{llll}
$\operatorname{lnPJ}$ & $-0.26409^{* * * *}$ & -20.74 & 0.000 \\
$\lambda_{1}$ & $-0.4934^{* * *}$ & -5.02 & 0.000 \\
$\lambda_{2}$ & $0.1898^{* * *}$ & 3.71 & 0.000 \\
$\lambda_{3}$ & $0.5816^{* * *}$ & 9.48 & 0.000 \\
Hansen test & & 267.27 & 1.000 \\
$\operatorname{AR}(1)$ & & -3.94 & 0.000 \\
$\operatorname{AR}(2)$ & 0.64 & 0.520 \\
\hline
\end{tabular}

Note: “***” stands for significance at $1 \%$ level.

682

683

684

685

686

687

688

689

690

691

692

693

694

695

696

697

698

699

700

701

702

703

704

705

706

707

708

709

710

711

712

713

714

\section{Conclusions and policy implications}

This study uses nightlight data to calculate the $\mathrm{CO}_{2}$ emissions of 268 cities in China from 2005 to 2017 and then employs the dynamic spatial Dubin model and intermediary effect model to explore the impact and transmission mechanism of PSA on $\mathrm{CO}_{2}$ emissions in China. Heterogeneity analysis is made from different regions, time nodes and different sub-industries. Furthermore, the dynamic threshold model is utilized to analyze the nonlinear characteristics of PSA on $\mathrm{CO}_{2}$ emissions under different degrees of government intervention. The results show that: (1) overall, China's $\mathrm{CO}_{2}$ emissions are path-dependent in the time dimension, that is, the $\mathrm{CO}_{2}$ emissions in the previous period will positively affect the current $\mathrm{CO}_{2}$ emissions, showing a "snowball effect". PSA not only significantly inhibits local $\mathrm{CO}_{2}$ emissions but also reduces $\mathrm{CO}_{2}$ emissions in adjacent areas through the spatial spillover effect. (2) Heterogeneity analysis shows that there are significant differences in the impact of PSA on China's $\mathrm{CO}_{2}$ emissions in different regions, time nodes and sub-divided industries. PSA significantly inhibited $\mathrm{CO}_{2}$ emissions in the eastern region, whereas significantly promoted the central and western regions; In the two stages before and after the o issued by the State Council in 2014, the impact of PSA on $\mathrm{CO}_{2}$ emissions changed from being insignificant to significant inhibition; Besides, there are differences in the impact of sub- industry agglomeration of producer services on $\mathrm{CO}_{2}$ emissions. Transportation, wholesale, retail and leasing services are at the low end of the value chain, and their agglomeration intensifies the $\mathrm{CO}_{2}$ emissions of local and surrounding cities; Information transmission computer service and software industry, financial industry, scientific research technology service and geological exploration industry have the advantages of technology driving and knowledge relevance. The agglomeration and development will not only reduce local $\mathrm{CO}_{2}$ emissions but also contribute to the $\mathrm{CO}_{2}$ emission reduction of surrounding areas. (3) The transmission mechanism test shows that PSA can indirectly inhibit $\mathrm{CO}_{2}$ emissions through economies of scale, industrial structure upgrading and technological innovation, among which technological innovation effect is leading first, followed by economies of scale and industrial structure. (4) The threshold effect shows that when government intervention is taken as the threshold, PSA has an obvious double threshold effect on China's $\mathrm{CO}_{2}$ emissions. When the level of government intervention is low, PSA inhibits $\mathrm{CO}_{2}$ emissions; with the increase of the level of government intervention, the impact of PSA on $\mathrm{CO}_{2}$ emissions changes from 
inhibition to promotion, indicating excessive government intervention will make PSA aggravate $\mathrm{CO}_{2}$ emissions.

Accordingly, this paper put forward the following policy implications:

(1) The local governments should increase support for producer services. On the one hand, they can promote the networked and intensive development of producer services through financial support, planning and layout and government guidance. On the other hand, while promoting the agglomeration and development of producer services in the city, accelerate the process of regional integration, encourage governments at all levels to strengthen exchanges and cooperation from the institutional level, break the institutional barriers to factor flow, guide the rational and free flow of innovation factors, and improve the allocation efficiency of innovation factors through cross-regional compensation mechanism and market-oriented mechanism, giving full play to the promotion effect of PSA on $\mathrm{CO}_{2}$ emission reduction in a larger space. In addition, in the process of energy conservation and emission reduction, Chinese local governments should adhere to the principle of combining territorial management with regional linkage, actively take joint defense measures, and investigate and control the inherent spatial effects of $\mathrm{CO}_{2}$ emissions.

(2) The local government should dynamically adjust industrial policies and take differential emission reduction measures in regions. The eastern region should take advantage of the good foundation for the development of the service industry, make full use of the advantages of capital and talents, improve the efficiency of scientific and technological innovation, guide the manufacturing industry to extend to the high-end value chain, create a rich and diverse productive service function gathering area with high integration through intensive and large-scale production mode, and strengthen complementarity, synergy and diversified development; The central and western regions should quickly build a communication bridge to learn advanced technologies and ideas, strive to break the restrictions on the development of local protectionism and producer services, make rational use of effective agglomeration, accelerate the spillover of technological innovation and the diffusion of knowledge. Particularly, the western region should give full play to its comparative advantages in policies, resources and labor force, cultivate productive service enterprises with stronger professionalism and higher integration with the local manufacturing industry, speed up infrastructure construction, increase the coverage of road network, strengthen vocational education and professional skill training, and actively participate in technical exchanges, cooperation and interaction in the eastern and central regions. In addition, in adjusting the structure and mode, all regions should further improve the development scale and speed of producer services, especially high-end producer services, promote the effective embedding of producer services in the manufacturing value chain, and promote the extension of manufacturing production links from high emission and low added value to both ends of low emission and high added value.

(3) As for the significant threshold effect of government intervention, local governments should take a moderate intervention. On one hand, they should provide policy guarantees and financial supports for the all-round development of PAS, such as providing preferential tax policies, improving public service facilities, strengthening 
the training and introducing high-end talents. Additionally, great efforts should be paid to reduce energy consumption by optimizing resource allocation to decrease $\mathrm{CO}_{2}$ emissions. On the other hand, market failure caused by excessive intervention should be avoided. Local governments should adhere to promoting market-oriented reform. In formulating industrial development policies, they should jointly deploy inter-industry cooperation and market-oriented reform, follow the law of industrial development, take the regional resource endowment, urban positioning and comparative advantage as the guidance, making the market play a decisive role in resource allocation.

Although this study has systematically examined the impact of PSA on $\mathrm{CO}_{2}$ emissions and the transmission mechanism, there are some limitations. This paper only takes the government intervention as the threshold variable to investigate the nonlinear characteristics between PSA and $\mathrm{CO}_{2}$ emissions. There may be more factors affecting the relationship between PSA and $\mathrm{CO}_{2}$ emissions, such as marketization, urbanization and so on, which need to be further explored in future research.

Authors Contributions Jinling Yan: Conceptualization, Project administration, Writing review \& editing, Writing original draft. Qiying Ran: Writing - review \& editing, Validation, Funding acquisition Supervision. Junfeng Zhao: Software, Visualization, Formal analysis, Funding acquisition, Supervision. Xiaodong Yang: Writing - review \& editing, Validation, Formal analysis. Xufeng Su: Methodology, Data curation. Chunxia Nie: Writing - review \& editing, Methodology, Funding acquisition.

Funding The authors acknowledge financial support from the National Natural Science Foundation of China (71463057), National Natural Science Foundation of China (41661112), the Xinjiang Uygur Autonomous Region Science and technology innovation strategy research special project (2021B04001-4), the Key Project of Plateau Discipline, Shanghai Business School (SWJJGYZX-2021-06), the Humanities and Social Sciences Program Chongqing Municipal Education Commission (18SKSJ034).

Data availability Not applicable.

\section{Declarations}

Ethical approval and consent to participate Not applicable.

Consent for publication Not applicable.

Conflict of interest The authors declare no competing interests.

\section{Reference:}

Abel, J. R., \& Deitz, R. (2011). The role of colleges and universities in building local human capital. Current issues in economics and finance, 17(6):1.

Ambec, S., Cohen, M. A., Elgie, S., \& Lanoie, P. (2013). The Porter hypothesis at 20: can environmental regulation enhance innovation and competitiveness?. Rev Env Econ Policy, 7(1):2-22.

Baron, R. M., \& Kenny, D. A., 1986. The moderator-mediator variable distinction in social psychological research: Conceptual, strategic, and statistical considerations. J Pers Soc Psychol, 51(6):1173.

Binbin, Y. (2018). The Agglomeration of Producer Services and Improve Energy Efficiency. Statistical Research, (04):30-40 (In Chinese). doi:10.19343/j.cnki.11-1302/c.2018.04.003.

Brock, W. A., \& Taylor, M. S. (2005). Economic growth and the environment: a review of theory and empirics. Handbook of economic growth, 1:1749-1821. 
Chen, C., Sun, Y., Lan , Q., \& Jiang, F. (2020a). Impacts of industrial agglomeration on pollution and ecological efficiency-A spatial econometric analysis based on a big panel dataset of China's 259 cities. J Clean Prod, 258:120721.

Chen, D., Chen, S., \& Jin, H. (2018). Industrial agglomeration and $\mathrm{CO}_{2}$ emissions: Evidence from 187 Chinese prefecture-level cities over 2005-2013. J Clean Prod, 172:993-1003.

Chen, J., Gao, M., Cheng, S., Hou, W., Song, M., Liu, X., Liu, Y. \& Shan, Y. (2020b). County-level $\mathrm{CO}_{2}$ emissions and sequestration in China during 1997-2017. Sci Data:7, 391.

Chen, S., Zhang, Y., Zhang, Y., \& Liu, Z. (2019). The relationship between industrial restructuring and China's regional haze pollution: A spatial spillover perspective. J Clean Prod, 239:115808.

Chen, Y., \& Lee, C. C. (2020). Does technological innovation reduce $\mathrm{CO}_{2}$ emissions? Cross-country evidence. J Clean Prod, 263:121550.

Cheng, Z. (2016). The spatial correlation and interaction between manufacturing agglomeration and environmental pollution. Ecol. Indic, 61:1024-1032.

Cox, P. M., Betts, R. A., Jones, C. D., Spall, S. A., \& Totterdell, I. J. (2000). Acceleration of global warming due to carbon-cycle feedbacks in a coupled climate model. Nature, 408(6809):184-187.

Ding, D., Pan, Z., Cuiuri, D., \& Li, H. (2015). Wire-feed additive manufacturing of metal components: technologies, developments and future interests. Int J Adv Manuf Tech, 81(1):465-481.

Dong, K., Sun, R., Jiang, H., \& Zeng, X. (2018). CO $\mathrm{CO}_{2}$ emissions, economic growth, and the environmental Kuznets curve in China: what roles can nuclear energy and renewable energy play?. J Clean Prod, 196:51-63.

Dong, Y., Shao, S., \& Zhang, Y. (2019). Does FDI have energy-saving spillover effect in China? A perspective of energy-biased technical change. J Clean Prod, 234:436-450.

Fang, J., Tang, X., Xie, R., \& Han, F. (2020). The effect of manufacturing agglomerations on smog pollution. Struct Change Econ D, 54:92-101.

Francois, J. F. (1990). Producer services, scale, and the division of labor. Oxford Economic Papers, 42(4): 715-729.

Govindaraju, V. C., \& Tang, C. F. (2013). The dynamic links between $\mathrm{CO}_{2}$ emissions, economic growth and coal consumption in China and India. Appl. Energy, 104:310-318.

Grossman, G. M., \& Krueger, A. B. (1995). Economic growth and the environment. Q J Econ, 110(2): 353-377.

Guo, Y., Tong, L., \& Mei, L. (2020). The effect of industrial agglomeration on green development efficiency in Northeast China since the revitalization. J Clean Prod, 258:120584.

Hao, Y., \& Liu, Y. M. (2015). Has the development of FDI and foreign trade contributed to China's CO 2 emissions? An empirical study with provincial panel data. Natural Hazards, 76(2):1079-1091.

Hao, Y., Gai, Z., \& Wu, H. (2020). How do resource misallocation and government corruption affect green total factor energy efficiency? Evidence from China. Energy Policy, 143:111562.

Huang, Y., Chen, X., Zhu, H., Huang, C., \& Tian, Z. (2019). The heterogeneous effects of FDI and foreign trade on $\mathrm{CO}_{2}$ emissions: evidence from China. Math Probl Eng, 2019.

Iammarino, S., Rodríguez-Pose, A., \& Storper, M. (2019). Regional inequality in Europe: evidence, theory and policy implications. J Econ Geogr, 19(2):273-298.

Jacobs, J., 2016. The economy of cities. Vintage: 162-164.

Jiang, Z., \& Lin, B. (2012). China's energy demand and its characteristics in the industrialization and urbanization process. Energy Policy, 49:608-615.

Kasman, A., \& Duman, Y. S. (2015). $\mathrm{CO}_{2}$ emissions, economic growth, energy consumption, trade and 
urbanization in new EU member and candidate countries: a panel data analysis. Econ Model, 44:97103.

Khan, M. K., Teng, J. Z., Khan, M. I., \& Khan, M. O. (2019). Impact of globalization, economic factors and energy consumption on $\mathrm{CO}_{2}$ emissions in Pakistan. Sci. Total Environ., 688:424-436.

Lan, F., Sun, L., \& Pu, W. (2021). Research on the influence of manufacturing agglomeration modes on regional carbon emission and spatial effect in China. Econ Model, 96:346-352.

Li Chengyu, Zhang Yongmei, Zhang Shiqiang, \& Wang Jianmei,. (2021). Applying the Super-EBM model and spatial Durbin model to examining total-factor ecological efficiency from a multidimensional perspective: evidence from China. Environ Sci Pollut Res:1-20.

Li, L., Hong, X., \& Peng, K. (2019). A spatial panel analysis of carbon emissions, economic growth and high-technology industry in China. Struct Change Econ D, 49: 83-92.

Li, W., Wang, W., Wang, Y., \& Qin, Y. (2017). Industrial structure, technological progress and $\mathrm{CO}_{2}$ emissions in China: Analysis based on the STIRPAT framework. Natural Hazards, 88(3):1545-1564.

Lin, B., \& Chen, Y. (2021). Towards the environmentally friendly manufacturing industry-the role of infrastructure. J Clean Prod:129387.

Lin, B., \& Chen, Z. (2018). Does factor market distortion inhibit the green total factor productivity in China?. J Clean Prod, 197: 25-33.

Liu, C. H., Rosenthal, S. S., \& Strange, W. C. (2020). Employment density and agglomeration economies in tall buildings. Reg Sci Urban Econ, 84:103555.

Liu, J., Zhao, Y., Cheng, Z., \& Zhang, H. (2018). The effect of manufacturing agglomeration on haze pollution in china. Int J Env Res Pub He, 15(11):2490.

Ma, J., Hou, Y., Wang, Z., \& Yang, W. (2021). Pricing strategy and coordination of automobile manufacturers based on government intervention and carbon emission reduction. Energy Policy, 148: 111919.

Marshall, A., \& Guillebaud, C. W., 1961. Principles of economics: An introductory volume. London: Macmillan.

Martínez-Zarzoso, I., \& Maruotti, A. (2011). The impact of urbanization on $\mathrm{CO}_{2}$ emissions: evidence from developing countries. Ecol Econ, 70(7): 1344-1353.

Pan, X., Xu, H., Song, M., Lu, Y., \& Zong, T. (2021). Forecasting of industrial structure evolution and $\mathrm{CO}_{2}$ emissions in Liaoning Province. J Clean Prod, 285:124870.

Ren-fa, Y. A. N. G. (2015). Whether industrial agglomeration can reduce environmental pollution or not. China Population, Resources and Environment, 25(02):23-29 (In Chinese).

Shahbaz, M., Solarin, S. A., Mahmood, H., \& Arouri, M. (2013). Does financial development reduce $\mathrm{CO}_{2}$ emissions in Malaysian economy? A time series analysis. Econ Model, 35: 145-152.

Shan, Y., Liu, J., Liu, Z., Xu, X., Shao, S., Wang, P., \& Guan, D. (2016). New provincial $\mathrm{CO}_{2}$ emission inventories in China based on apparent energy consumption data and updated emission factors. Appl. Energy, 184:742-750.

Shanzi, Ke, Ming He \& Chenhua Yuan (2014). Synergy and Co-agglomeration of Producer Services and Manufacturing: A Panel Data Analysis of Chinese Cities, Reg Stud, 48(11):18291841. DOI: $10.1080 / 00343404.2012 .756580$.

Shao, S., Tian, Z., \& Yang, L. (2017). High speed rail and urban service industry agglomeration: evidence from China's Yangtze River Delta region. J Transp Geogr, 64:174-183.

Shen, N., \& Peng, H. (2021). Can industrial agglomeration achieve the emission-reduction effect?. Socio-Econ Plan Sci, 75:100867. 
Sun, W., \& Huang, C. (2020). How does urbanization affect carbon emission efficiency? Evidence from China. J Clean Prod, 272:122828.

Tan, X., Dong, L., Chen, D., Gu, B., \& Zeng, Y. (2016). China's regional $\mathrm{CO}_{2}$ emissions reduction potential: A study of Chongqing city. Appl. Energy, 162:1345-1354.

Tian, X., Bai, F., Jia, J., Liu, Y., \& Shi, F. (2019). Realizing low-carbon development in a developing and industrializing region: Impacts of industrial structure change on $\mathrm{CO}_{2}$ emissions in southwest China. J. Environ. Manage, 233:728-738.

Wang Liguo \& Ju Lei. (2012). Local Government Intervention, Enterprise Overinvestment and Over Capacity :26 Industry Samples. Reform, (12):52-62 (In Chinese). doi: CNKI:SUN:REFO.0.2012-12007.

Wang, K. L., Zhao, B., Ding, L. L., \& Miao, Z. (2021). Government intervention, market development, and pollution emission efficiency: Evidence from China. Sci. Total Environ., 757: 143738.

Wang, R., \& Tan, J. (2021). Exploring the coupling and forecasting of financial development, technological innovation, and economic growth. Technol Forecast Soc, 163:120466.

Wang, S., Li, G., \& Fang, C. (2018a). Urbanization, economic growth, energy consumption, and $\mathrm{CO}_{2}$ emissions: Empirical evidence from countries with different income levels. Renew. Sust. Energ. Rev., 81: 2144-2159.

Wang, Y., \& Zheng, Y. (2021). Spatial effects of carbon emission intensity and regional development in China. Environ Sci Pollut Res, 28(11):14131-14143.

Wang, Y., Yan, W., Ma, D., \& Zhang, C. (2018b). Carbon emissions and optimal scale of China's manufacturing agglomeration under heterogeneous environmental regulation. J Clean Prod, 176:140150.

Wang, Z., \& Zhu, Y. (2020). Do energy technology innovations contribute to $\mathrm{CO}_{2}$ emissions abatement? A spatial perspective. Sci. Total Environ., 726:138574.

Wei, L., \& Wu, Y. (2021). The Influence of Government-Led Industrial Agglomeration on the Efficiency of Resource Allocation-Evidence from 30 Provinces in China over 2000-2017. American Journal of Industrial and Business Management, 11(2):157-171.

Wen, Y., \& Liao, M. (2019). The Impact of Industrial Agglomeration on Carbon Emissions: Empirical Evidence from China. International Journal of Management and Sustainability, 8(2): 67-78.

Wu, H., Hao, Y., \& Weng, J. H. (2019). How does energy consumption affect China's urbanization? New evidence from dynamic threshold panel models. Energy policy, 127:24-38.

Wu, H., Li, Y., Hao, Y., Ren, S., \& Zhang, P. (2020a). Environmental decentralization, local government competition, and regional green development: Evidence from China. Sci. Total Environ., 708:135085.

Wu, H., Xu, L., Ren, S., Hao, Y., \& Yan, G. (2020b). How do energy consumption and environmental regulation affect carbon emissions in China? New evidence from a dynamic threshold panel model. Resour. Policy, 67:101678.

Wu, J. N., Cao, Y. H., \& Cheng, S. B. (2013). The Study of Spatial Pattern Characteristics and Evolution Process of Producer Services in Nanjing. Econ Geogr, (02):105-110 (In Chinese). doi:10.15957/j.cnki.jjd1.2013.02.015.

Wu, J., Xu, H., \& Tang, K. (2021a). Industrial agglomeration, $\mathrm{CO}_{2}$ emissions and regional development programs: A decomposition analysis based on 286 Chinese cities. Energy, 225:120239.

Wu, R., Wang, J., Wang, S., \& Feng, K. (2021b). The drivers of declining $\mathrm{CO}_{2}$ emissions trends in developed nations using an extended STIRPAT model: A historical and prospective analysis. Renew. Sust. Energ. Rev., 149:111328. 
Xi, Y. (2016). Excessive Agglomeration and Labor Crowding Effect: An Empirical Study of China's Manufacturing Industry. Am. Int. J. Humanit. Soc. Sci, 2(2): 45-54.

Xie, R., Yao, S., Han, F., \& Fang, J. (2019). Land finance, producer services agglomeration, and green total factor productivity. Int Regional Sci Rev, 42(5-6):550-579.

Yang, H., Lu, F., \& Zhang, F. (2020). Exploring the effect of producer services agglomeration on China's energy efficiency under environmental constraints. J Clean Prod, 263:121320.

Yang, H., Zhang, F., \& He, Y. (2021). Exploring the effect of producer services and manufacturing industrial co-agglomeration on the ecological environment pollution control in China. Environ Dev Sustain:1-26.

Yu, Y., \& Du, Y. (2019). Impact of technological innovation on $\mathrm{CO}_{2}$ emissions and emissions trend prediction on 'New Normal'economy in China. Atmospheric Pollut. Res., 10(1): 152-161.

Yuan, H., Feng, Y., Lee, C. C., \& Cen, Y. (2020). How does manufacturing agglomeration affect green economic efficiency?. Energy Econ, 92: 104944.

Zhang, F., Deng, X., Phillips, F., Fang, C., \& Wang, C. (2020a). Impacts of industrial structure and technical progress on carbon emission intensity: Evidence from 281 cities in China. Technol Forecast Soc, 154:119949.

Zhang, J., Jiang, H., Liu, G., \& Zeng, W. (2018). A study on the contribution of industrial restructuring to reduction of carbon emissions in China during the five Five-Year Plan periods. J Clean Prod, 176:629-635.

Zhang, K., Shao, S., \& Fan, S. (2020b). Market integration and environmental quality: Evidence from the Yangtze river delta region of China. J. Environ. Manage, 261:110208.

Zhang, Y. J., \& Da, Y. B. (2015). The decomposition of energy-related carbon emission and its decoupling with economic growth in China. Renew. Sust. Energ. Rev., 41:1255-1266.

Zhang, Z., \& Zhao, W. (2018). Research on financial pressure, poverty governance, and environmental pollution in China. Sustainability, 10(6):1834.

Zhang, Z., Wang, Z., \& Liang, S. (2021). The effect of government intervention on the resource misallocation in innovation: ownership differences. Asia-Pacific J Account Econ:1-17.

Zhao, B., \& Yang, W. (2020). Does financial development influence $\mathrm{CO}_{2}$ emissions? A Chinese provincelevel study. Energy, 200:117523.

Zhao, J., Dong, X., \& Dong, K. (2021). How does producer services' agglomeration promote carbon reduction?: The case of China. Econ Model, 104:105624.

\section{Statements \& Declarations}

The authors declare that they have no known competing financial interests or personal relationships that could have appeared to influence the work reported in this paper. 